\title{
The Development of the Renewable Energy Technologies in Spain
}

\author{
Félix Hernández ${ }^{1}$, Miguel Hernández-Campos ${ }^{2}$ \\ ${ }^{1}$ Institute of Economics, Geography and Demography (Spanish National Research Council), Madrid, Spain; ${ }^{2}$ Foundation Gómez Pardo, \\ Madrid, Spain. \\ Email: felix.hernandez@cchs.csic.es
}

Received February $16^{\text {th }}, 2011$; revised March $14^{\text {th }}, 2011$; accepted March $18^{\text {th }}, 2011$.

\begin{abstract}
This article examines the development of the four main renewable energy technologies (RET) in Spain in the latest years: biomass, small hydro $(\mathrm{SH})$, solar photovoltaic (solar PV) and wind. It has been studied the variation of the working time per MW installed available from the on line data base of Spanish National Commission on Energy (SNCE), in the national context and in each of the Autonomic Communities (AACC). We have also obtained the marginal cost curve of the global RE. The main conclusions of the study are that Spain is effective meeting the RE generation target but not efficient in costs and in short term it is not any RETs that can achieve competitive price comparing to the electrical market.
\end{abstract}

Keywords: Renewable Energy Technologies, Working Time per MW, Feed-in Tariff, Marginal Cost Curve of the Global $R E$

\section{Introduction}

Most of EU governments have adopted measures aimed in promoting of the Renewable Energy Technologies (RETs). The degree of success of these measures has been variable in terms of efficiency in costs and deployment effectiveness [1]. Spain has been cited as an example for its success to get more RETs in place through a feed-in tariff (FIT) system, but there are serious concerns about their rising costs. In fact, FIT are the most effective system to a rapid deployment of RETs, but when it is in place the installations capacity (in MW) increase spectacularly, often with undesirable effects. For example, in the future some RETs could not survive financially unless their subsidies come at the expense of customers. Wang [2] already warned that Spain had to drastically reduce its FIT payments to Solar PV projects and impose caps on annual installed capacity of this TER.

It is necessary therefore to find a comparative parameter that gives some light about the rhythm installed capacity in relation with the number of annual full load hours of the RETs. Couture and Gagnon [3] speak about the per-kWh payments adjusted on the number of annual full load hours, referring this term to the hypothetical number of hours in which a RET would need to operate to produce its annual production.

The current paper studies the development of the different RETs in Spain in the latest years. It embraces the following special regimen ${ }^{1}$ technologies: biomass, small hydro (SH), solar photovoltaic (solar PV) and wind. All of these are subsidized by the administration through a FIT system, added to the cogeneration, wastes and wastes treatment ${ }^{2}$, not include in this paper.

Based on the empirical data provided from www. cne.es [4] by the Spanish National Commission on Energy (SNCE) reported for March $10^{\text {th }}, 2010$, all the RETs have been analyzed developing an accurate tool that correlates the variation of working hours recorded during the annual production of GWh per MW installed, according to the Spanish and all Autonomic Communities (AACC). The evolution of the equivalent FIT $^{3}$ will be examine as well as a percentage of the total retribution by the sold

${ }^{1}$ In Spain technologies of special regime charge a FIT in the electricity price and include all RET and cogeneration, wastes and treatment of wastes. The latter is excluded of the RET, as opposed some EU country. ${ }^{2}$ Wastes and waste treatment are not considered RET by the Spanish law. However, both of these are included in the RETs in some of the EU member countries.

${ }^{3}$ Equivalent FIT is defined in the RD 485/2009 of the fourth of April of 2009 as the difference between the regulated tariff established and the settlement carried out for the sale of energy generated from renewable energy. 
energy and the contribution per MW for all the RETs. Finally, a marginal cost curve has been obtained from the global Renewable Energy in Spain.

\section{Variation of Working Hours per MW Installed}

As a comparative parameter of the developing of all the different RETs it has been chosen the calculated working hours according to the sold GWh per MW installed, from the on line data base of SNCE. Their development with time makes possible to estimate the fulfilment of each RETs in the electric market. In fact the working hours of RETs represents the amortized income with the sale of the produced work in GWh by the whole power plants of each RETs; the installed capacity in $\mathrm{MW}^{4}$ is the total capital to be amortized; its quotient means the amortized index in hours/MW units. The increase of this index with time belongs to a positive integration of the RET in the electric market system. Oppositely, a decrease means lack of competitiveness of the RET in the energy market.

\subsection{National Context (National Market)}

The Figure $\mathbf{1}^{5}$, represents the fluctuations between working hours recorded in the sale of RET per MW installed, in the period 2004 - 2009, of the RETs mentioned above: biomass, $\mathrm{SH}$, solar $\mathrm{PV}$ and wind.

As additional information from the development of the working hours per MW of the sold RETs, the following Table 1 represents the maximum variation in percentage from the main value for all the RETs.

From the brief analysis of the Figure 1 it can infer the following items:

- The variable working hours per MW tends to change for each RET:

o Almost draws a symmetric function in the $\mathrm{SH}^{6}$.

o Describes a decreasing smooth line for biomass and wind and a decreasing sharply slope in the Solar PV, due to the following causes (alternative or simultaneous):

Lack of planning between the development of power plants (installed capacity increasing) and the sold working hours per MW covered by the FIT system (decreasing). ${ }^{7}$

${ }^{4}$ European Commission [5] gives a relation between the capacity and the investment cost for biomass (1,124-1,406 €/MW); SH (1,700 €/MW) and wind energy $(900 € / \mathrm{MW})$.

${ }^{5}$ In the legend of the Figure the y axis on the left side is the reference of the RET followed by PA in brackets, and on the right side when the RET is followed by SA in the brackets.

${ }^{6} \mathrm{SH}$ feedback is due to the abundance or lack of this resource each year, which defines the framework of sold energy per MW installed. It has an unpredictable short term behavior.

${ }^{7}$ This is a common problem in Spain regarding to construction permissions provided by the Autonomic Community of new Power Plants, however, the regulation of the FIT system is leaded by the National Administration

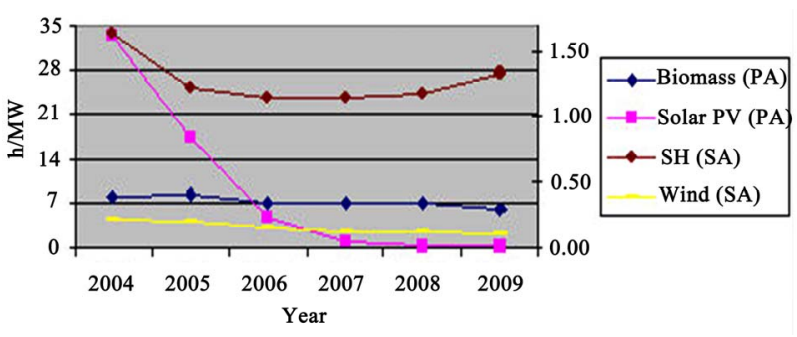

Figure 1. Working hours per MW.

Table 1. Maximum variation of working hours per MW respect the average.

\begin{tabular}{cc}
\hline RET & Variation respect the average (\%) \\
\hline Biomass & 19.5 \\
SH & 36.8 \\
Wind & 60.5 \\
Solar PV & 346.8 \\
\hline
\end{tabular}

- Gradual reduction in the technological potential in the RETs.

- Problems to adjust the energy generation and the electrical demand.

- Decrease in the electrical demand.

- Punctual fall in the renewable resources.

The Table 1 shows that in the case of the Solar PV, the working time variation respect to the average is large (346.8), which means sharply variations in the energy generated for this technology in the period $2004-2009$, that is to say, this represents an unsustainable developing of this RET [6] linked to its high FIT ${ }^{8}$.

\subsection{AACC Context}

The Table 2 includes the variation $\eta$ between the sold working hours per MW installed in the period 2007 $2009^{9}\left(\mathrm{WH}_{2007}-\mathrm{WH}_{2009}\right)$, by the SNCE, with regard the first year recorded $2007\left(\mathrm{WH}_{2007}\right)$. The variation has been calculated for all the RETs and AACC from the on line data base of SNCE.

From the Table 2 we have built the Figure 2. It shows the variation of $\eta$, divided in regular intervals, in the period 2007 - 2009 for all AACC. The Figure illustrates the change in relative frequency of the RETs, number of times the value $\eta$ appears in the corresponding row, in relation to the interval of hours per MW considered in the Table. In fact, each RET has a maximum for a different interval: $56.3 \%$ for SH and $\eta<0 ; 40.0 \%$ for biomass and $46.7 \%$ for wind and $25 \% \leq \eta \leq 50 \%$, and $41.2 \%$ for Solar PV and $50 \% \leq \eta \leq 75 \%$.

${ }^{8} \mathrm{~A}$ recent monitoring report from the SNCE shows many irregularities related to the working hours recorded in the Solar PV plants.

${ }^{9} \mathrm{As}$ it has been said before, the information provided from the SNCE is reported until March $10^{\text {th }}, 2010$.

${ }^{10}$ No data is recorded from 2007 in this AC. 
Table 2. Percentage variation of $\eta$ (2007 - 2009).

\begin{tabular}{|c|c|c|c|c|c|c|}
\hline \multirow{3}{*}{$\mathrm{AACC}$} & \multirow{3}{*}{ RET } & \multicolumn{5}{|c|}{$\begin{array}{c}\text { Percentage variation } \\
\eta=\left(\mathrm{WH}_{2007}-\mathrm{WH}_{2009}\right) / \mathrm{WH}_{2007} * 100\end{array}$} \\
\hline & & \multirow{2}{*}{$\eta<0$} & \multicolumn{4}{|c|}{ Interval variation of $\eta \%$} \\
\hline & & & $0-25$ & $25-50$ & $50-75$ & $75-100$ \\
\hline \multirow{4}{*}{ Andalucía } & Biomass & & & 35.8 & & \\
\hline & $\mathrm{SH}$ & -44.7 & & & & \\
\hline & Solar PV & & & & & 86.5 \\
\hline & Wind & & & 45.9 & & \\
\hline \multirow{4}{*}{ Aragón } & Biomass & & & & 51.1 & \\
\hline & $\mathrm{SH}$ & -5.7 & & & & \\
\hline & Solar PV & & & & & 89.6 \\
\hline & Wind & & & 25.1 & & \\
\hline \multirow{4}{*}{ Asturias } & Biomass & & & & 52.7 & \\
\hline & SH & & 14.2 & & & \\
\hline & Solar PV & & & & 59.0 & \\
\hline & Wind & & & & 52.8 & \\
\hline \multirow{3}{*}{ Baleares } & Solar PV & & & & & 97.3 \\
\hline & Wind & & & & 58.8 & \\
\hline & Biomass & -105.3 & & & & \\
\hline \multirow{4}{*}{ Canarias } & $\mathrm{SH}$ & & & & 68.0 & \\
\hline & Solar PV & -234.0 & & & & \\
\hline & Wind & & 16.1 & & & \\
\hline & Biomass & & & 32.4 & & \\
\hline \multirow{4}{*}{ Cantabria } & $\mathrm{SH}$ & & 13.1 & & & \\
\hline & Solar PV & & & & 52.4 & \\
\hline & Wind & -4.5 & & & & \\
\hline & Biomass & & 15.1 & & & \\
\hline \multirow{4}{*}{ Castilla La Mancha } & $\mathrm{SH}$ & -9.4 & & & & \\
\hline & Solar PV & & & & 54.3 & \\
\hline & Wind & & 22.7 & & & \\
\hline & Biomass & -99.5 & & & & \\
\hline \multirow{4}{*}{ Castilla León } & $\mathrm{SH}$ & -0.1 & & & & \\
\hline & Solar PV & & & & 58.1 & \\
\hline & Wind & & & 43.4 & & \\
\hline & Biomass & & 13.7 & & & \\
\hline Cataluñ & SH & -66.9 & & & & \\
\hline Catatuna & Solar PV & & & & 60.8 & \\
\hline & Wind & & & & 51.8 & \\
\hline Fxtremadura & $\mathrm{SH}$ & -20.8 & & & & \\
\hline & Solar PV & -326.1 & & & & \\
\hline & Biomass & & 22.8 & & & \\
\hline Galicia & $\mathrm{SH}$ & -17.5 & & & & \\
\hline Gallcia & Solar PV & & & & 71.0 & \\
\hline & Wind & & & 30.0 & & \\
\hline & Biomass & & & 44.2 & & \\
\hline I a Rioia & $\mathrm{SH}$ & & 22.3 & & & \\
\hline La K1oja & Solar PV & & & & & 79.5 \\
\hline & Wind & & & 30.9 & & \\
\hline & Biomass & & & 34.3 & & \\
\hline Madrid & $\mathrm{SH}$ & & 10.9 & & & \\
\hline & Solar PV & & & & 60.8 & \\
\hline & Biomass & & & & & 81.3 \\
\hline Mumir & SH & & 14.2 & & & \\
\hline Murcia & Solar PV & & & 32.4 & & \\
\hline & Wind & & & 33.1 & & \\
\hline & Biomass & -23.0 & & & & \\
\hline Sto & SH & & & 36.7 & & \\
\hline Navarra & Solar PV & & & 48.6 & & \\
\hline & Wind & & 24.1 & & & \\
\hline & Biomass & & & 35.5 & & \\
\hline País Vasco & SH & -9.4 & & & & \\
\hline Pals vasco & Solar PV & & & 43.3 & & \\
\hline & Wind & & & 29.0 & & \\
\hline & Biomass & & & 35.8 & & \\
\hline Valencia & SH & -271.5 & & & & \\
\hline Valencia & Solar PV & & & 37.4 & & \\
\hline & Wind & & & & 61.7 & \\
\hline
\end{tabular}




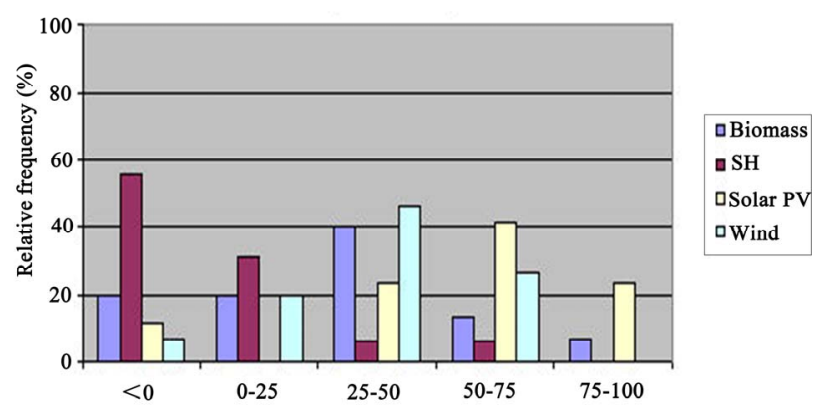

Figure 2. Percentege de variation hours per MW (2007 2009).

The Table 2 and the Figure 2 show the state of development of RETs in all AACC in relation to $\eta$. The negative sign points out that the degree of development it trends to rise, and decreasing as $\eta$, variation between the sold working hours per MW installed in the period 2007 - 2009, is growing up. Thus, we can infer that $\mathrm{SH}$ is the technology which development is raising the most among all the RETs and Solar PV is decreasing in the majority of AACC. We can also establish the following particularities from the $\eta$ values:

- In Canarias ${ }^{10}$, Castilla León and Navarra the biomass has grown $105.3 \%, 99.5 \%$ and $23.0 \%$ respectively.

- In Canarias the SH has decreased $68.0 \%$.

- Exceptionally, the Solar PV has grown in Canarias $(234.0 \%)$ and Extremadura (326.1\%), and the wind in Cantabria (4.5\%).

- In Navarra, sold working hours of SH, Solar PV and wind per MW has decreased harmoniously, becoming a rational initiative for the legal authorization granting a regulated utility to construct a RETs power plant In Canarias the $\mathrm{SH}$ has decreased $68.0 \%$ (see note 6).

\section{Evolution of the Net Equivalent FIT per MW Installed}

The concept of feed in tariff it is really useful to check out the development of each RET comparing their competitiveness to the whole electricity market. According with definition above established by the SNCE, the equivalent feed in tariff is the difference between the total retribution received for each RET and the total energy multiplied by the annual regular price in the electrical market. Therefore it is the cost of RET calculated from the on line data base of SNCE by reference of the con-

${ }^{11}$ The tons of $\mathrm{CO}_{2}$ avoided have been obtained per each year from the energy mix. Source: www.idae.es.

${ }^{12}$ The total amount of the emissions avoided has been calculated by the average prize of the EU emissions market in the latest two years in $€ /$ Ton of $\mathrm{CO}_{2}$ (Source: Electric and Business System of $\mathrm{CO}_{2}$ Emissions RightsSENDECO2). ventional energy incorporating the effect of the support policies in a straightforward way. Costs are expressed in terms of the minimal price that the investor has to obtain from the market over the lifetime of the production capacity in order to make the construction of additional capacity (or the production with existing capacity) attractive.

In order to calculate the equivalent FIT it has just been considered the power plants that had sold the energy directly through the electrical market or by a private agreement with a distribution company with negotiated fares and other alternative markets. So far, the net equivalent FIT it has been obtained as the subtraction of the equivalent FIT minus the avoided emissions ${ }^{11}$ cost for all the RETs $^{12}$ analyzed.

The temporally development of the net equivalent FIT per MW installed, it works out as a very useful tool for checking how alike it is each RET from the competitive electricity market. This is considerate an effective indicator to analyze the prospects for diffusion of each RET, equivalent to a learning curve [7]. The Table 3 shows the net equivalent FIT per MW installed during the period 2004 - 2009 that belongs to the Spanish situation.

From Table 3 it can be achieved two main conclusions:

- The development of the FIT per MW installed shows maximums in the latest year of 2009 and a minimum value en the first collected years 2004 and 2005.

- Therefore, it is not achieved any competitive price comparing to the electrical market by any RET.

In the Figure 3 it is shown the changes in the net equivalent FIT, calculated from the on line data base of SNCE as a percentage of the total received retribution by the annual generated energy for each RET. If the functions are adjusted to a logarithmic tendency line, it is confirmed that the percentage of the equivalent FIT relative to the total received retribution from the different studied RETs tends to acquire in short terms values near $38.4 \%$ in the case of SH; $39.6 \%$ in wind energy; $50.9 \%$ in biomass, and $87.8 \%$ in solar PV.

From the Figure 3 it can be figure out the following statement:

All the drawn lines as it is shown in Figure 4 tends to increase with time, which involves low competitiveness in short term, although the biomass has the highest slope that means a bigger gap with the electrical market price comparing to other RETs.

\section{Marginal Cost Curve of the Global Renewable Energy}

The marginal cost curve of the global Renewable Energy, biomass, Solar PV, SH and wind energy included, has been traced as a function of the percentage of RET (quo- 
Table 3. Net equivalent FIT per MW installed development (Thousands $€ / \mathrm{MW}$ )*.

\begin{tabular}{ccccc}
\hline \multirow{2}{*}{ Year } & \multicolumn{4}{c}{ Technology } \\
\cline { 2 - 5 } & Biomass & Wind & SH & Solar PV \\
\hline 2004 & 91.231 & $39.611^{*}$ & 69.465 & $255.734^{*}$ \\
2005 & $87.524^{*}$ & 44.447 & $47.591^{*}$ & 281.763 \\
2006 & 113.757 & 59.472 & 64.805 & 265.397 \\
2007 & 157.475 & 55.913 & 63.601 & 271.203 \\
2008 & 198.268 & 59.296 & 61.723 & 281.964 \\
2009 & $275.132^{\#}$ & $70.849^{\#}$ & $102.947^{\#}$ & $696.069^{\#}$ \\
\#: it represents the maximums values; & & \\
${ }^{*}:$ it represents the minimums ones. & &
\end{tabular}

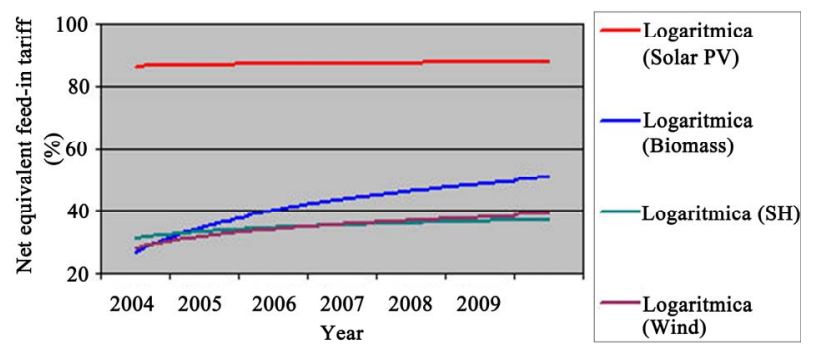

Figure 3. Net equivalent feed-in tariff for each RET.

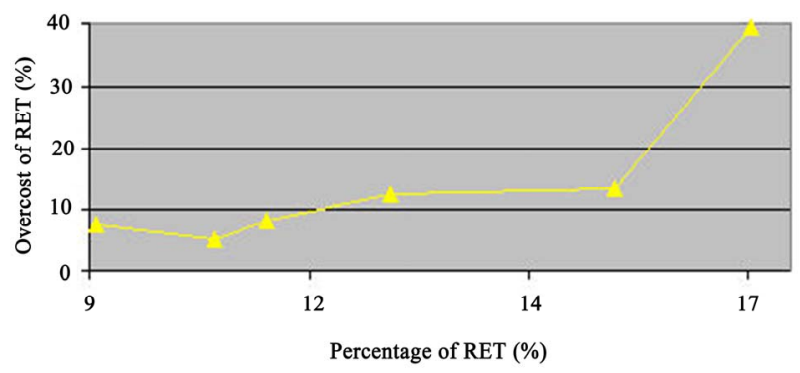

Figure 4. Marginal cost curve of RET.

tient between RET and the sold total energy at electrical market) that has contributed to the electricity generation (x axis in Figure 4). This curve shows the evolution of the additional cost of the RET in percentage respect the total retribution by the sold total energy at electrical market price (y axis in Figure 4). All the parameters necessary for the calculation has been taking from the on line data base of SNCE. This curve represents a test of effectiveness to achieve the Spanish target (rising of the global TER) versus their efficiency in costs (increasing overcost of RET) [8].

The data represented in the Figure 4, belongs to the period from 2004 to 2009, both inclusive. From its profile it can be achieved two main remarks:

- The function grows respect the x-axis, which means a good approach to meet its annual target in Renewable Electricity Generation, that is to say, the policy to achieve the Spanish objective in RE gen- eration is resulting effective.

- The last track of the curve, belonged to year 2009, entailed a huge increase of over cost remaining to the most expensive RET, Solar PV source, whose GWh sold in the electrical market it has been duplicated this year, therefore the policy to achieve the Spanish objective in RE generation is not efficiency in costs.

\section{Conclusions}

Conclusions can be categorized in three principal groups:

\subsection{Principal Conclusions}

The two main conclusions of the study are:

- The policy to achieve the Spanish objective in RE generation is resulting effective but not efficiency in costs.

- In short term it is not any RETs that can achieve competitive price comparing to the electrical market, particularly the biomass has a bigger gap with the electrical market price comparing to other RETs.

\subsection{National Context}

The variable working hours per MW is a curve almost symmetric for the SH, decreasing smooth for biomass and wind and decreasing sharply for the Solar PV. The decreasing slope can be caused by

- Lack of planning between the increasing development of the RETs power and the decreasing sold working hours per MW covered by the FIT system.

- Gradual reduction in the technological potential in the RET.

- Problems to adjust the energy generation and the electrical demand.

- Decrease in the electrical demand.

- Punctual fall in the renewable resources.

In the case of the Solar PV, its high FIT represents an unsustainable developing of this RET.

\subsection{AACC Context}

$\mathrm{SH}$ is the technology which development is raising the most among all the TERs and Solar PV is decreasing in the majority of AACC. We can also establish the following conclusions particular:

- In the period 2007 - 2009, the Solar PV has grown exceptionally in Canarias (234.0\%) and Extremadura (326.1\%), and the wind in Cantabria (4.5\%). It is also singular that $\mathrm{SH}$ has decreased $68.0 \%$ in $\mathrm{Ca}-$ narias.

- In Navarra, the development of SH, Solar PV and wind has decreased harmoniously, becoming a rational initiative for the legal authorization granting a regulated utility to construct a RETs power plant. 


\section{REFERENCES}

[1] P. Komor and M. Bazilian, "Renewable Energy Policy Goals, Programs and Technologies," Energy Policy, Vol. 33, No. 14, 2005, pp. 1873-1881. doi:10.1016/j.enpol.2004.03.003

[2] U. Wang, "Spain: The Solar Frontier No More," Greentech Media, May 2009, accessed at 2 June 2009. www.greentechmedia.com

[3] T. Couture and Y. Gagnon, "An Analysis of Feed-in Tariff Remuneration Models: Implication of Renewable Energy Investment," Energy Policy, Vol. 38, 2010, pp. 955-965. doi:10.1016/j.enpol.2009.10.047

[4] CNE, "CNE Renewable Energy Statistics," 2010. www.cne.es
[5] European Commission, "Sustainable Energy Technology Reference Information System (SETRIS),” Joint Research Centre European, 2004. www.jrc.es

[6] J. Anta "El Mix de Generación Eléctrica a Future," 2010. www.energiaysociedad.es

[7] L. Neij, "Use of Experience Curves to Analyse the Prospects for Diffusion and Adoption of Renewable Energy Technology," Energy Policy, Vol. 25, No. 13, 1997, pp. 1099-1107. doi:10.1016/S0301-4215(97)00135-3

[8] P. Del Río, F. Hernández and M. Gual, “The Implications of Kyoto Project Mechanisms for the Deployment of Renewable Electric In Europe," Energy Policy, Vol. 33, No. 15, 2005, pp. 2010-2022. doi:10.1016/j.enpol.2004.03.022 